Research

Open Access

\title{
Phenylephrine versus norepinephrine for initial hemodynamic support of patients with septic shock: a randomized, controlled trial
}

\author{
Andrea Morelli1, Christian Ertmer ${ }^{2}$, Sebastian Rehberg ${ }^{2}$, Matthias Lange ${ }^{2}$, Alessandra Orecchioni ${ }^{1}$, \\ Amalia Laderchi ${ }^{1}$, Alessandra Bachetoni ${ }^{3}$, Mariadomenica D'Alessandro ${ }^{3}$, Hugo Van Aken², \\ Paolo Pietropaoli ${ }^{1}$ and Martin Westphal ${ }^{2}$
}

\begin{abstract}
1Department of Anesthesiology and Intensive Care, University of Rome, 'La Sapienza', Viale del Policlinico 155, Rome 00161, Italy ${ }^{2}$ Department of Anesthesiology and Intensive Care, University Hospital of Muenster, Albert-Schweitzer-Straße 33, Muenster 48149, Germany

3Laboratory of Clinical Pathology, Department of Surgery, University of Rome, 'La Sapienza', Viale del Policlinico 155, Rome 00161, Italy
\end{abstract}

Corresponding author: Andrea Morelli, andrea.morelli@uniroma1.it

Received: 20 Oct 2008 Revisions requested: 5 Nov 2008 Revisions received: 12 Nov 2008 Accepted: 18 Nov 2008 Published: 18 Nov 2008

Critical Care 2008, 12:R143 (doi:10.1186/cc7121)

This article is online at: http://ccforum.com/content/12/6/R143

(c) 2008 Morelli et al.; licensee BioMed Central Ltd.

This is an open access article distributed under the terms of the Creative Commons Attribution License (http://creativecommons.org/licenses/by/2.0), which permits unrestricted use, distribution, and reproduction in any medium, provided the original work is properly cited.

\begin{abstract}
Introduction Previous findings suggest that a delayed administration of phenylephrine replacing norepinephrine in septic shock patients causes a more pronounced hepatosplanchnic vasoconstriction as compared with norepinephrine. Nevertheless, a direct comparison between the two study drugs has not yet been performed. The aim of the present study was, therefore, to investigate the effects of a firstline therapy with either phenylephrine or norepinephrine on systemic and regional hemodynamics in patients with septic shock.

Methods We performed a prospective, randomized, controlled trial in a multidisciplinary intensive care unit in a university hospital. We enrolled septic shock patients $(n=32)$ with a mean arterial pressure below $65 \mathrm{mmHg}$ despite adequate volume resuscitation. Patients were randomly allocated to treatment with either norepinephrine or phenylephrine infusion $(n=16$ each) titrated to achieve a mean arterial pressure between 65 and $75 \mathrm{mmHg}$. Data from right heart catheterization, a thermodye dilution catheter, gastric tonometry, acid-base
\end{abstract}

homeostasis, as well as creatinine clearance and cardiac troponin were obtained at baseline and after 12 hours. Differences within and between groups were analyzed using a two-way analysis of variance for repeated measurements with group and time as factors. Time-independent variables were compared with one-way analysis of variance.

Results No differences were found in any of the investigated parameters.

Conclusions The present study suggests there are no differences in terms of cardiopulmonary performance, global oxygen transport, and regional hemodynamics when phenylephrine was administered instead of norepinephrine in the initial hemodynamic support of septic shock.

Trial registration ClinicalTrial.gov NCT00639015

\section{Introduction}

The current guidelines for the management of patients with septic shock recommend norepinephrine or dopamine as firstline agents to increase peripheral vascular resistance and to preserve organ perfusion following adequate volume therapy [1]. Moreover, the Surviving Sepsis Campaign recommends that phenylephrine should not be used as the initial vasopres- sor in septic shock [1], since phenylephrine may reduce splanchnic blood flow and oxygen delivery in septic shock patients $[2,3]$. Nevertheless, it is important to note that these recommendations are based on a limited number of studies that have evaluated the clinical use of phenylephrine in septic shock $[2,4,5]$. More importantly, a direct comparison between 
phenylephrine and norepinephrine in human septic shock has not yet been performed.

In contrast to norepinephrine that stimulates $\alpha_{1}$ and $\alpha_{2}$ receptors, and to a lower extent $\beta_{1}$ and $\beta_{2}$ receptors, phenylephrine is a selective $\alpha_{1}$-receptor agonist mainly constricting larger arterioles and having virtually no effects on terminal arterioles [6].

Krejci and colleagues recently compared the effects of norepinephrine and phenylephrine on microcirculatory blood flow in multiple abdominal organs in a porcine model of sepsis [7]. Whereas the norepinephrine-induced increase in perfusion pressure was associated with blood flow distribution away from the mesenteric circulation, phenylephrine did not impair the mesenterial blood flow distribution - suggesting possible beneficial properties of phenylephrine on hepatosplanchnic perfusion in septic shock.

In contrast, previous studies have reported that a delayed administration of phenylephrine replacing norepinephrine in a series of septic shock patients caused a more pronounced hepatosplanchnic vasoconstriction as compared with norepinephrine $[2,8]$.

In the past few years, it has become evident that the efficacy of hemodynamic optimization by fluids and vasopressor agents critically depends on the urgency of therapy [1,9-11]. In this regard, it is conceivable that the negative effects of hepatosplanchnic perfusion noticed in response to phenylephrine administration [2,8] might have been related to a delayed treatment [11].

On this basis, we hypothesized that - compared with norepinephrine - early administration of phenylephrine does not worsen hepatosplanchnic perfusion during initial hemodynamic support of patients with septic shock. We therefore conducted a randomized, double-blind, controlled clinical trial to compare the effects of a first-line therapy with either phenylephrine or norepinephrine infusion on systemic and regional hemodynamics in patients with septic shock.

\section{Materials and methods} Patients

After approval by the Local Institutional Ethics Committee, the study was performed in an 18-bed multidisciplinary intensive care unit (ICU) of the Department of Anesthesiology and Intensive Care of the University of Rome 'La Sapienza'. Informed consent was obtained from the patients' next of kin, as the patients were sedated and mechanically ventilated and thus were unable to give consent themselves. Enrollment of the patients started in December 2007 and ended in July 2008. This study has been registered as ClinicalTrial.gov NCT00639015. We enrolled patients who fulfilled the criteria of septic shock [1] presenting with a mean arterial pressure
(MAP) below $65 \mathrm{mmHg}$ despite appropriate volume resuscitation (pulmonary artery occlusion pressure (PAOP) $=12$ to 18 $\mathrm{mmHg}$ and central venous pressure $=8$ to $15 \mathrm{mmHg}$ ) [1]

Exclusion criteria were age $<18$ years, pronounced cardiac dysfunction (that is, cardiac index $\leq 2.2 \mathrm{l} / \mathrm{min} / \mathrm{m}^{2}$ in the presence of PAOP $>18 \mathrm{mmHg}$ ), chronic renal failure, severe liver dysfunction (Child-Turcotte-Pugh grade $\mathrm{C}$ ), significant valvular heart disease, present coronary artery disease, pregnancy, and present or suspected acute mesenteric ischemia.

All patients received mechanical ventilation using a volumecontrolled mode with a plateau pressure maintained below 30 $\mathrm{cmH}_{2} \mathrm{O}$ [1]. All patients were appropriately analgo-sedated using sufentanil and midazolam.

\section{Measurements}

Systemic hemodynamic monitoring of the patients (Vigilance ${ }^{\circledR}$ II; Edwards Lifesciences, Irvine, CA, USA) involved a pulmonary artery catheter (7.5-F; Edwards Lifesciences) and a radial artery catheter (20 G; Arrow International Inc, Reading, PA, USA). The MAP, right atrial pressure, mean pulmonary arterial pressure, and PAOP were measured at end expiration. The heart rate was analyzed from a continuous recording of the electrocardiogram with ST segments monitored. The cardiac index was measured using the continuous thermodilution technique (Vigilance ${ }^{\circledR}$ II; Edwards Lifesciences). The stroke volume index, systemic vascular resistance index, pulmonary vascular resistance index, left ventricular stroke work index, right ventricular stroke work index, oxygen delivery index, oxygen consumption index, and oxygen extraction ratio were calculated using standard formulae. Arterial and mixed-venous blood samples were taken for measuring oxygen tensions and saturations, as well as carbon dioxide tensions, standard bicarbonate, arterial base excess, $\mathrm{pH}$, and arterial lactate. In addition, arterial blood samples were drawn for the determination of cardiac troponin I and creatinine concentrations.

Regional hemodynamic monitoring of the patients was performed with a 4-F oximetry thermodye dilution catheter (PV2024L; Pulsion Medical Systems AG, Munich, Germany) inserted through the femoral artery for the determination of the plasma disappearance rate of indocyanine green (PDR) and the blood clearance of indocyanine green related to body surface area (CBI). Moreover, an air tonometer (Tonocap; DatexOhmeda, Helsinki, Finland) was inserted via the nasogastric route for gastric mucosal carbon dioxide tension measurement.

The PDR and CBI were determined with the thermodye dilution method as assessed by the Cold Z-021 (Pulsion Medical Systems AG) using an established protocol [12,13]. Every value was calculated as the mean of three measurements, each consisting of a bolus of $0.3 \mathrm{mg} / \mathrm{kg}$ indocyanine green at $2 \mathrm{mg} / \mathrm{ml}$ (Pulsion Medical Systems AG) in ice-cold 5\% glu- 
cose solution injected into the right atrium. In addition, the gradient between gastric mucosal and arterial $\mathrm{pCO}_{2}$ was calculated, which has been shown to be more appropriate for the detection of regional ischemia than for the calculation of mucosal $\mathrm{pH}[14,15]$. Urine samples were collected to assess urinary output and creatinine clearance in the laboratory setting.

\section{Study design}

Patients who met the entry criteria were randomized using a computer-based procedure, to receive either an infusion of phenylephrine or norepinephrine in a double-blinded fashion for 12 hours. The two study drugs were titrated to maintain a MAP between 65 and $75 \mathrm{mmHg}$. Serial fluid challenges were performed to maintain the central venous pressure at 8 to 15 $\mathrm{mmHg}$ and the PAOP between 12 and $18 \mathrm{mmHg}$ during the 12-hour intervention period [1]. Packed red blood cells were transfused when hemoglobin concentrations decreased below $8 \mathrm{~g} / \mathrm{dl}$. If the mixed-venous oxygen saturation was $<65 \%$ despite appropriate arterial oxygenation (arterial oxygen saturation $\geq 95 \%$ ) and hemoglobin concentrations $\geq 8 \mathrm{~g} /$ $\mathrm{dl}$, dobutamine was administered (with a maximum dose of 20 $\mu \mathrm{g} / \mathrm{kg} / \mathrm{min}$ ) to achieve mixed-venous oxygen saturation values $\geq 65 \%$ [1]. Systemic, pulmonary and regional hemodynamic measurements, laboratory variables, and blood gases were determined at baseline and 12 hours after randomization. Creatinine clearance was determined over a period of 12 hours.

At the end of the 12-hour study period, study drugs were gradually reduced and switched to open-labeled norepinephrine. If necessary, dobutamine was given according to the study protocol mentioned above.

\section{Statistical analyses}

The main endpoint of the present study was the modifications of the PDR and $\mathrm{CBI}$ after phenylephrine administration as compared with the norepinephrine group. To detect a 30\% difference in one of the measured variables (that is, PDR and $\mathrm{CBI}$ ) with an expected standard deviation of $30 \%$, a test power of $80 \%$ and an $\alpha$-error probability of $P<0.05$, a sample size of 16 subjects per group was required [16]. Data are expressed as the mean \pm standard deviation, if not otherwise specified. Sigma Stat 3.10 software (SPSS, Chicago, IL, USA) was used for statistical analysis.

After confirming the normal distribution of all variables (Kolmogorov-Smirnov test), differences within and between groups were analyzed using a two-way analysis of variance for repeated measurements with group and time as factors. Timeindependent variables were compared with one-way analysis of variance. In the case of significant group differences over time, appropriate post hoc comparisons (Student-NewmanKeuls test) were performed. Categorical data were compared using the chi-square test. For all tests, an $\alpha$-error probability of $P<0.05$ was considered statistically significant.

\section{Results \\ Patients}

After screening 62 patients with septic shock who met the inclusion criteria of the study, 30 patients had to be excluded due to prior catecholamine therapy $(n=26)$, inappropriately low cardiac output $(n=2)$, or chronic renal failure $(n=2)$. Finally, 32 consecutive patients were enrolled in the study and equally randomized into the two study groups ( $n=16$ per group) (Figure 1).

\section{Demographic data}

Baseline characteristics including age, gender, body weight, origin of septic shock, and Simplified Acute Physiology Score II are presented in Table 1. There were no significant differences in baseline characteristics between groups, except for a higher body weight in the norepinephrine group. No differences were found between the phenylephrine and norepinephrine groups in the mean time elapsed from ICU admission to the need for vasopressor support (39 \pm 35 hours versus $37 \pm$ 38 hours, $P=0.282$ ). In this regard, vasopressor administrations were initiated as soon as the inclusion criteria were met (with no time delay).

\section{Study drug requirements and systemic hemodynamics}

The amount of fluids infused during the study period in the phenylephrine and norepinephrine groups was similar $(2,554$ $\pm 1,140 \mathrm{ml}$ versus $2,431 \pm 1,010 \mathrm{ml}, P=0.751$ ). Phenylephrine dosages were higher than those for norepinephrine 12 hours after randomization $(P<0.001)$ (Figure 2$)$. The goal MAP of 65 to $75 \mathrm{mmHg}$ was reached in all subjects. Twelve hours after randomization, the MAP was significantly higher in the norepinephrine group as compared with patients treated with phenylephrine $(P=0.011)$ (Figure 3$)$. This difference remained, however, within the predefined threshold MAP of 65 to $75 \mathrm{mmHg}$. There were no significant differences between groups in any other variable of systemic hemodynamics (Figure 3 and Table 2).

Whereas the heart rate significantly decreased in both study groups $(P=0.009$ and $P=0.022$ for phenylephrine and norepinephrine treatment versus baseline, respectively), the systemic vascular resistance index and the left ventricular stroke work index both increased as compared with baseline (each $P$ $<0.001)$. The pulmonary vascular resistance index increased with time only in the phenylephrine group $(P=0.02$ versus baseline). Six patients in the norepinephrine group as well as eight patients in the phenylephrine group received dobutamine during the study period (chi-square test: not significant and $P=0.722$, respectively). The dobutamine requirements, however, were similar between the two groups $(15 \pm 5 \mu \mathrm{g} / \mathrm{kg} / \mathrm{min}$ versus $14 \pm 6 \mu \mathrm{g} / \mathrm{kg} / \mathrm{min}, P=0.35)$. The incidence of new-onset tachyarrhythmias was $2 / 16$ in the phenylephrine and $1 / 16$ in the norepinephrine group (chi-square test: not significant and $P=1.0$, respectively). 


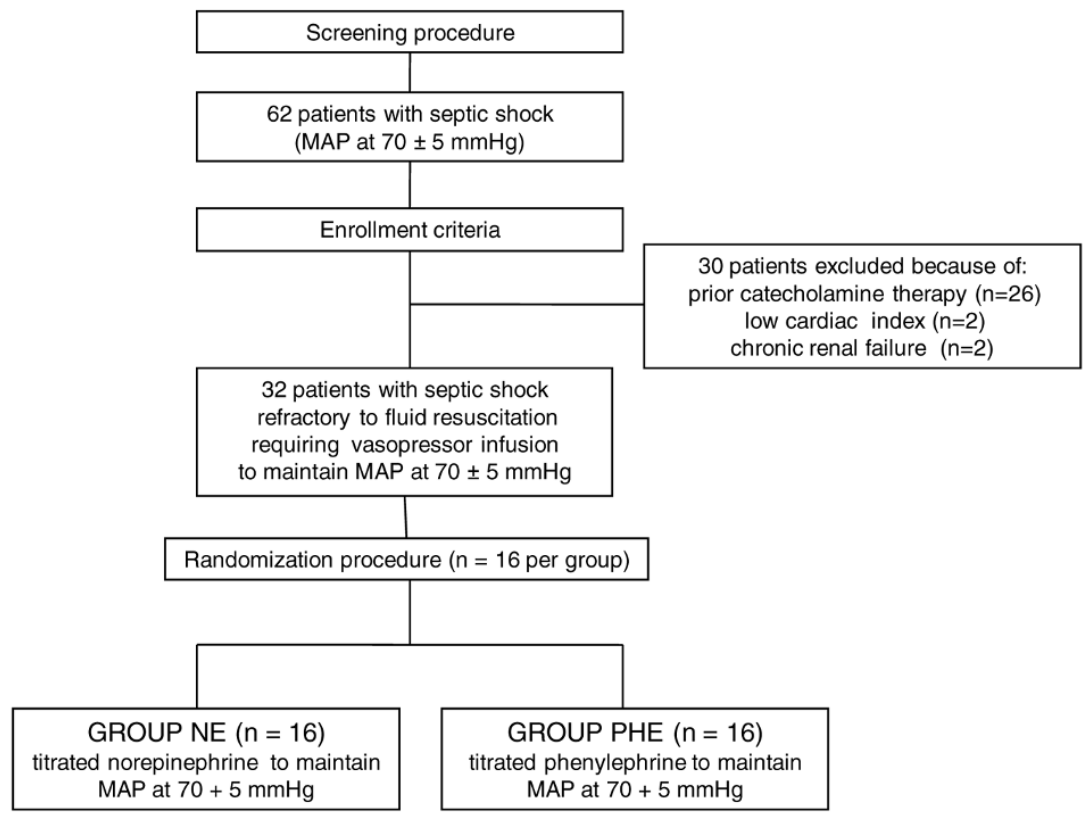

Study design. MAP, mean arterial pressure; NE, norepinephrine; $\mathrm{PHE}$, phenylephrine.

\section{Regional hemodynamics, acid-base homeostasis, and oxygen transport variables}

There were no significant overall differences between groups in any variable of regional hemodynamics, acid-base homeostasis, or oxygen transport (Figure 4 and Table 3 ).

\section{Variables of organ function and injury}

Urine output and creatinine clearance were similar between groups throughout the 12-hour interventional period $(P=$ 0.170 and $P=0.609$, respectively) (Figure 5). Likewise, troponin I plasma concentrations were comparable between groups (Table 2).

\section{Length of ICU stay and outcome}

The length of ICU stay and the ICU mortality were similar between groups (Table 1).

\section{Discussion}

The major findings of the present study are that, when administered as a first-line vasopressor agent in septic shock patients, phenylephrine did not worsen hepatosplanchnic perfusion as compared with norepinephrine, had similar effects as norepinephrine on cardiopulmonary performance and global oxygen transport, and was less effective than norepinephrine to counteract sepsis-related arterial hypotension as reflected by the higher dosages required to achieve the same goal MAP.

Table 1

Baseline characteristics of study patients

\begin{tabular}{|c|c|c|c|}
\hline & Phenylephrine $(n=16)$ & Norepinephrine $(n=16)$ & $P$ value \\
\hline Age (years) & 70 (53 to 74$)$ & 70 (59 to 74$)$ & 0.850 \\
\hline Gender (percentage male) & 75 & 56 & 0.457 \\
\hline Simplified Acute Physiology Score II & $57 \pm 8$ & $55 \pm 7$ & 0.434 \\
\hline Cause of septic shock & $\begin{array}{l}\text { Pneumonia }(n=7) \text {, peritonitis }(n=8) \text {, } \\
\text { meningitis }(n=1)\end{array}$ & $\begin{array}{l}\text { Pneumonia }(n=8) \text {, peritonitis }(n=8) \text {, } \\
\text { meningitis }(n=0)\end{array}$ & 0.587 \\
\hline Mortality (n (\%)) & $10 / 16(63 \%)$ & $9 / 16(56 \%)$ & 1.000 \\
\hline Intensive care unit length of stay (days) & 16 (7 to 25$)$ & 16 (10 to 24$)$ & 0.597 \\
\hline
\end{tabular}

Data presented as median ( $25 \%$ to $75 \%$ range) or mean \pm standard deviation unless otherwise indicated. 


\section{Vasopressor dosage}

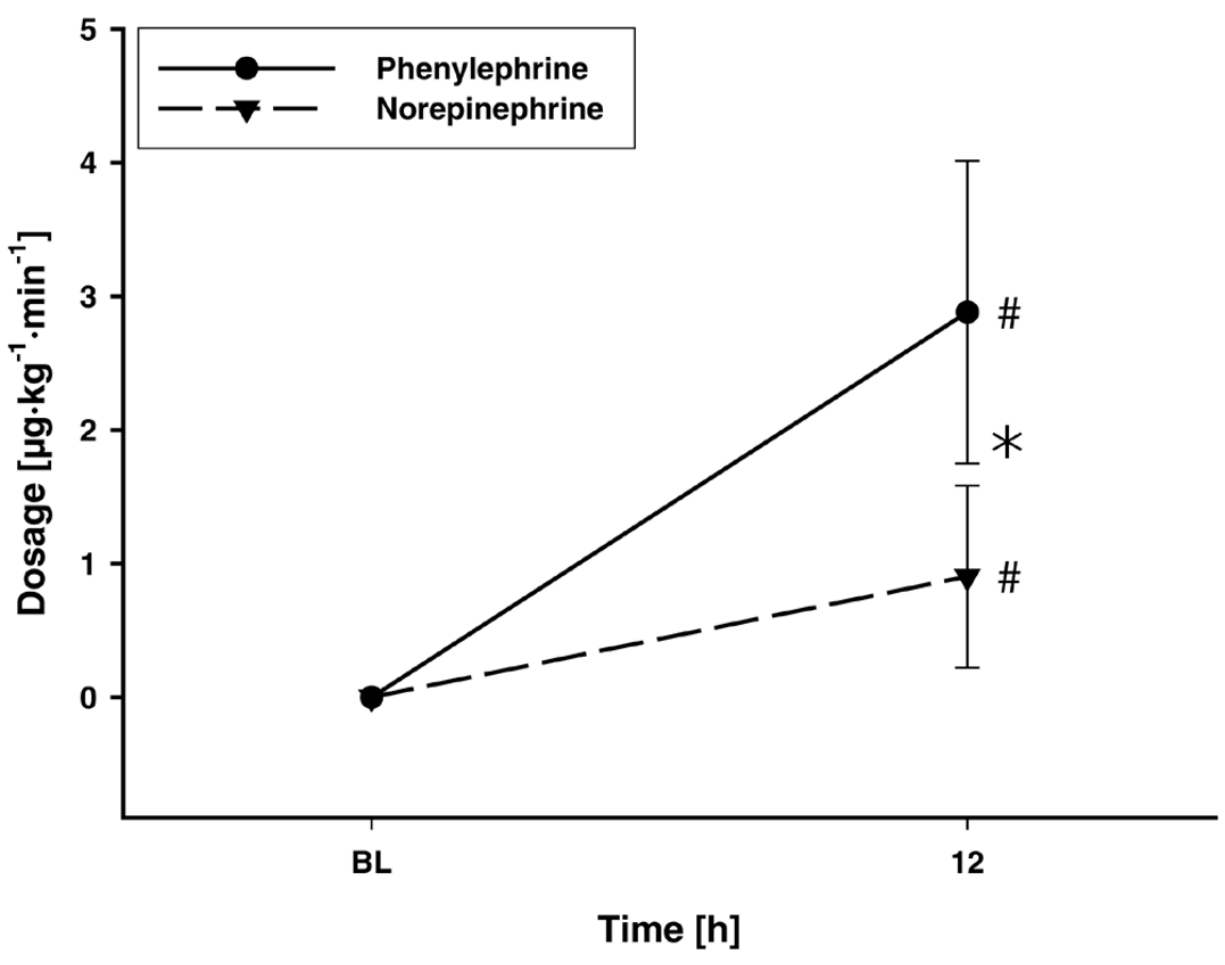

Study drug requirements of study patients. Vasopressor dosage throughout the study. $\# P<0.05$ versus baseline (BL) (significant time effect). ${ }^{\star} P$ $<0.05$, phenylephrine versus norepinephrine.

Phenylephrine increases systemic vascular resistance by selectively stimulating $\alpha_{1}$ adrenoceptors without a compensatory increase in myocardial contractility, and thus in cardiac output [6]. From a hemodynamic point of view, it might be argued that, in volume-resuscitated patients, norepinephrine may potentially be advantageous over phenylephrine, since it simultaneously stimulates $\alpha_{1}, \beta_{1}$ and $\beta_{2}$ receptors, thereby counteracting arterial hypotension by increasing systemic vascular resistance and possibly myocardial inotropy [6]. On the other hand, phenylephrine could be preferable over norepinephrine, since $\beta_{1}$-receptor stimulation may increase the heart rate and myocardial oxygen demand. In this regard, a previous study reported that prolonged tachycardia may increase the incidence of major cardiac events in critically ill patients [17].

In the present study we did not find any differences between groups treated with either norepinephrine or phenylephrine in terms of systemic hemodynamics. We recently reported that, in a series of septic shock patients, the systemic hemodynamics and global oxygen transport remained unchanged after replacing norepinephrine with phenylephrine except for a significant decrease in heart rate [8]. The different severity of the cardiovascular dysfunction among the studied patients, however, could have affected the results of the latter study [8]. In addition, the investigated patients were already treated with high norepinephrine dosages $(0.8 \pm 0.7 \mu \mathrm{g} / \mathrm{kg} / \mathrm{min})$ at study entry. It is therefore conceivable that - different from delayed treatment [8] - early administration of phenylephrine in the hypotensive patients enrolled in the present study could have played a pivotal role in this regard.

Nevertheless, at the end of the study period, phenylephrine dosages were higher than (that is, 220\%) those for norepinephrine to maintain the predefined threshold MAP. Although a comparative dose-finding study in human septic shock has not yet been performed, our observation suggests that phenylephrine may be less effective as compared with norepinephrine to counteract arterial hypotension when high dosages of catecholamines are required.

Clinical evidence indicates that infusion of norepinephrine doses ranging from 0.01 to $3 \mu \mathrm{g} / \mathrm{kg} / \mathrm{min}$ neither worsen splanchnic perfusion nor compromise organ function in the presence of septic shock [3,18-24].

Whereas only few clinical studies including a small number of patients have been performed on phenylephrine in septic shock $[2,4,5,8]$, several studies have evaluated the impact of 

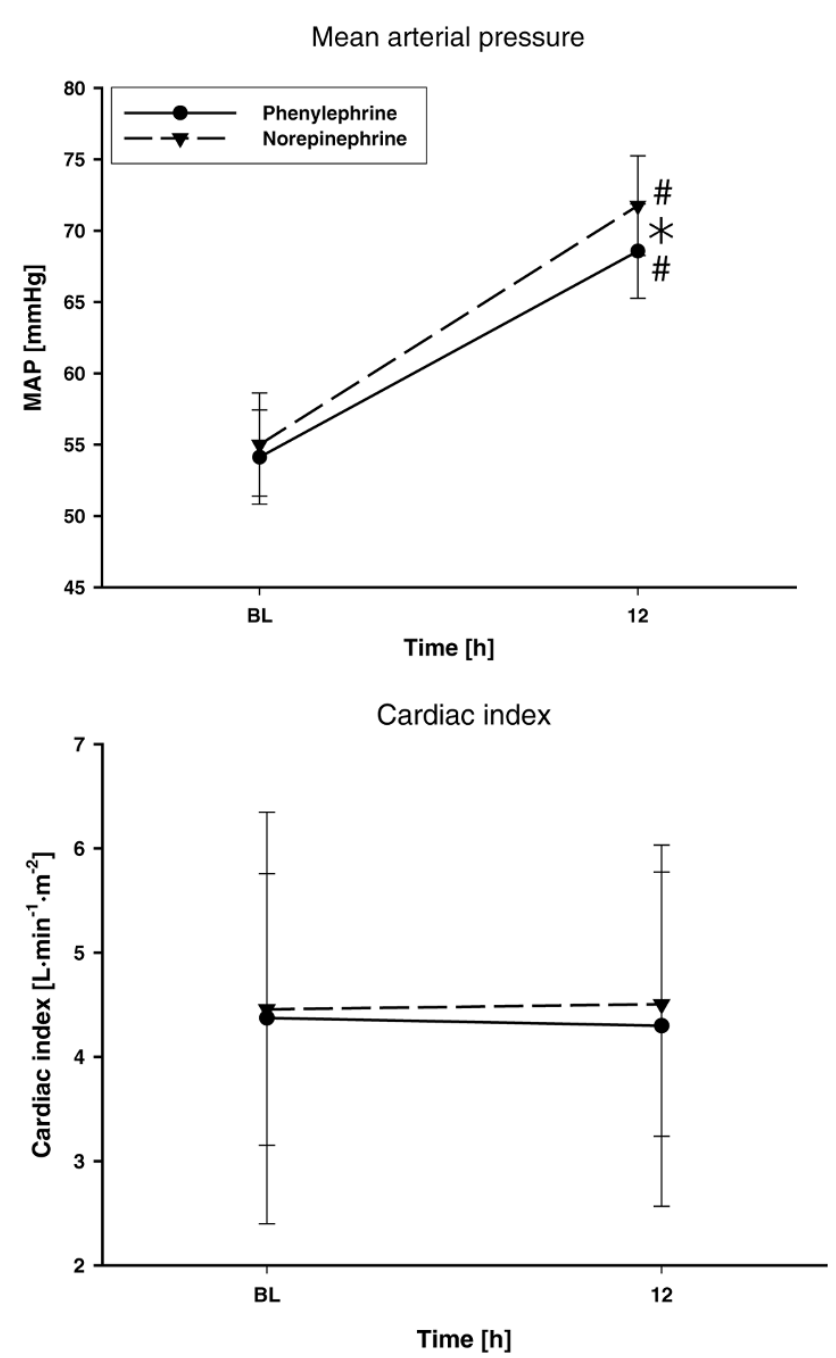

Heart rate

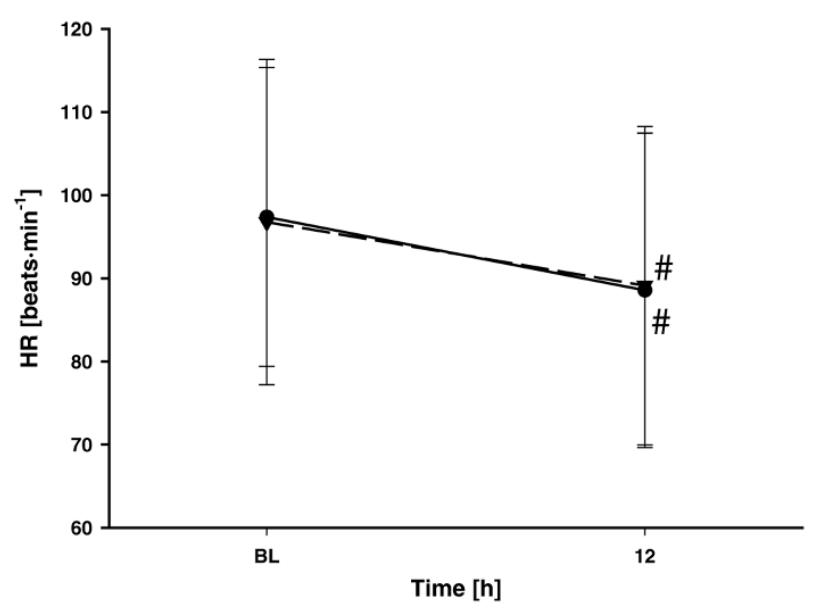

Systemic vascular resistance index

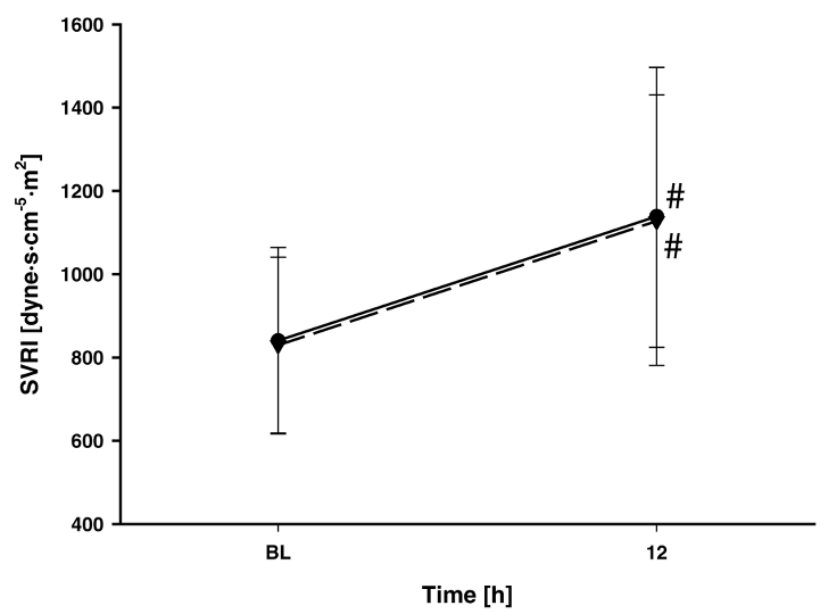

Systemic hemodynamics of study patients. Patients' mean arterial pressure (MAP), heart rate (HR), cardiac index, and systemic vascular resistance index (SVRI) throughout the study. ${ }^{\#} P<0.05$ versus baseline (BL) (significant time effect). ${ }^{\star} P<0.05$, norepinephrine versus phenylephrine.

phenylephrine on splanchnic perfusion in experimental septic shock. In this regard, Breslow and colleagues reported no differences between phenylephrine $(5.9 \pm 2.7 \mu \mathrm{g} / \mathrm{kg} / \mathrm{min})$ and norepinephrine $(3.0 \pm 1.6 \mu \mathrm{g} / \mathrm{kg} / \mathrm{min})$ in terms of the splanchnic oxygen supply [25]. These findings were confirmed by Schwarz and colleagues, who reported that - despite major differences in systemic hemodynamics - progressively increasing phenylephrine from 0.1 to $10 \mu \mathrm{g} / \mathrm{kg} / \mathrm{min}$ did not decrease jejunal tissue oxygen supply as compared with norepinephrine (from 0.01 to $2 \mu \mathrm{g} / \mathrm{kg} / \mathrm{min}$ ) [18]. In endotoxemic dogs, Zhang and colleagues likewise demonstrated that $1 \mu \mathrm{g} /$ $\mathrm{kg} / \mathrm{min}$ phenylephrine influenced neither hepatosplanchnic blood flow nor global and liver oxygen extraction capabilities [26]. Krejci and colleagues reported recently that norepinephrine in doses of $0.7 \pm 0.3 \mu \mathrm{g} / \mathrm{kg} / \mathrm{min}$ distributes blood flow away from the splanchnic circulation (for example, small intestine) to other regions of the body by the $\beta$-adrenergic stimulation [7]. Importantly, whereas norepinephrine reduced blood flow in both the jejunal mucosa and in the jejunal muscularis, phenylephrine at doses of $3.1 \pm 1.0 \mu \mathrm{g} / \mathrm{kg} / \mathrm{min}$ did not affect blood flow in the jejunal mucosa and even increased blood flow in the jejunal muscularis. It is therefore conceivable that an $\alpha_{1}$-receptor agonist such as phenylephrine -due to the lack of the $\beta$-adrenergic stimulation - may be beneficial in septic shock, because it increases blood pressure without causing negative effects on tissue blood flow.

In the clinical setting, Reinelt and colleagues reported that hepatosplanchnic oxygen delivery and blood flow decreased in six septic shock patients when norepinephrine was gradu- 
Table 2

\begin{tabular}{|c|c|c|c|}
\hline & Baseline & 12 hours & $P$ value \\
\hline Pulmonary artery occlusion pressure $(\mathrm{mmHg})$ & & & 1.000 \\
\hline Phenylephrine & $15 \pm 2$ & $17 \pm 3^{\star}$ & \\
\hline Norepinephrine & $15 \pm 2$ & $17 \pm 3^{*}$ & \\
\hline Right atrial pressure $(\mathrm{mmHg})$ & & & 0.902 \\
\hline Phenylephrine & $13 \pm 3$ & $15 \pm 3^{*}$ & \\
\hline Norepinephrine & $13 \pm 3$ & $14 \pm 3^{*}$ & \\
\hline Mean pulmonary arterial pressure $(\mathrm{mmHg})$ & & & 0.521 \\
\hline Phenylephrine & $28 \pm 9$ & $33 \pm 11^{*}$ & \\
\hline Norepinephrine & $27 \pm 5$ & $30 \pm 4^{*}$ & \\
\hline Pulmonary vascular resistance index (dyne.s/cm5 $/ \mathrm{m}^{2}$ ) & & & 0.330 \\
\hline Phenylephrine & $293 \pm 253$ & $348 \pm 296^{*}$ & \\
\hline Norepinephrine & $235 \pm 103$ & $264 \pm 105$ & \\
\hline Right ventricular stroke work index ( $\mathrm{g} / \mathrm{m}^{2} /$ beat) & & & 0.564 \\
\hline Phenylephrine & $9 \pm 5$ & $12 \pm 7^{*}$ & \\
\hline Norepinephrine & $8 \pm 4$ & $11 \pm 4^{\star}$ & \\
\hline Left ventricular stroke work index ( $\mathrm{g} / \mathrm{m}^{2} /$ beat) & & & 0.721 \\
\hline Phenylephrine & $25 \pm 11$ & $35 \pm 14^{\star}$ & \\
\hline Norepinephrine & $25 \pm 8$ & $37 \pm 9^{*}$ & \\
\hline Stroke volume index $\left(\mathrm{g} / \mathrm{m}^{2} /\right.$ beat $)$ & & & 0.963 \\
\hline Phenylephrine & $45 \pm 18$ & $49 \pm 19$ & \\
\hline Norepinephrine & $46 \pm 13$ & $50 \pm 11$ & \\
\hline Cardiac troponin I (ng/ml) & & & 0.854 \\
\hline Phenylephrine & $1.0 \pm 0.9$ & $1.1 \pm 0.9$ & \\
\hline Norepinephrine & $0.9 \pm 0.9$ & $1.1 \pm 0.8$ & \\
\hline
\end{tabular}

${ }^{\star} P<0.05$ versus baseline (significant time effect).

ally replaced by phenylephrine at identical levels of MAP and cardiac index [2]. Our research group reported recently that, in a series of 15 septic shock patients, whereas phenylephrine did not impair gastrointestinal mucosal perfusion as measured by the gradient between gastric mucosal and arterial $\mathrm{pCO}_{2}$, it decreased hepatosplanchnic perfusion as indicated by a decrease in the PDR and CBI associated with a slight increase in arterial lactate concentration [8]. The latter study, however, was designed as a cross-over study replacing norepinephrine infusion with phenylephrine and then once again replacing with norepinephrine after 8 hours. Importantly, the patients involved were already treated with high norepinephrine dosages at study entry.

In the present study, phenylephrine administration did not negatively affect gastrointestinal perfusion (that is, the gradient between gastric mucosal and arterial $\mathrm{pCO}_{2}$ ) when compared with norepinephrine as first-line therapy in septic shock patients. The absence of detrimental splanchnic hemodynamic effects of phenylephrine during the observation period is further confirmed by the lack of overall differences between groups in terms of the PDR, CBI, acid-base homeostasis, as well as arterial lactate concentrations.

There are several reasons helping to explain the discrepancies between studies. First, in the studies of Reinelt and colleagues and of Morelli and colleagues, the MAP at baseline was 65 to $75 \mathrm{~mm} \mathrm{Hg}[2,8]$, whereas it was considerably lower in the present study. Second, the mean time elapsed from meeting the criteria for study entry to infusion of phenylephrine was about 32 hours in the cited studies [2,8]. By contrast, in the present study, a different hemodynamic condition at baseline (that is, arterial hypotension) and, more importantly, the admin- 

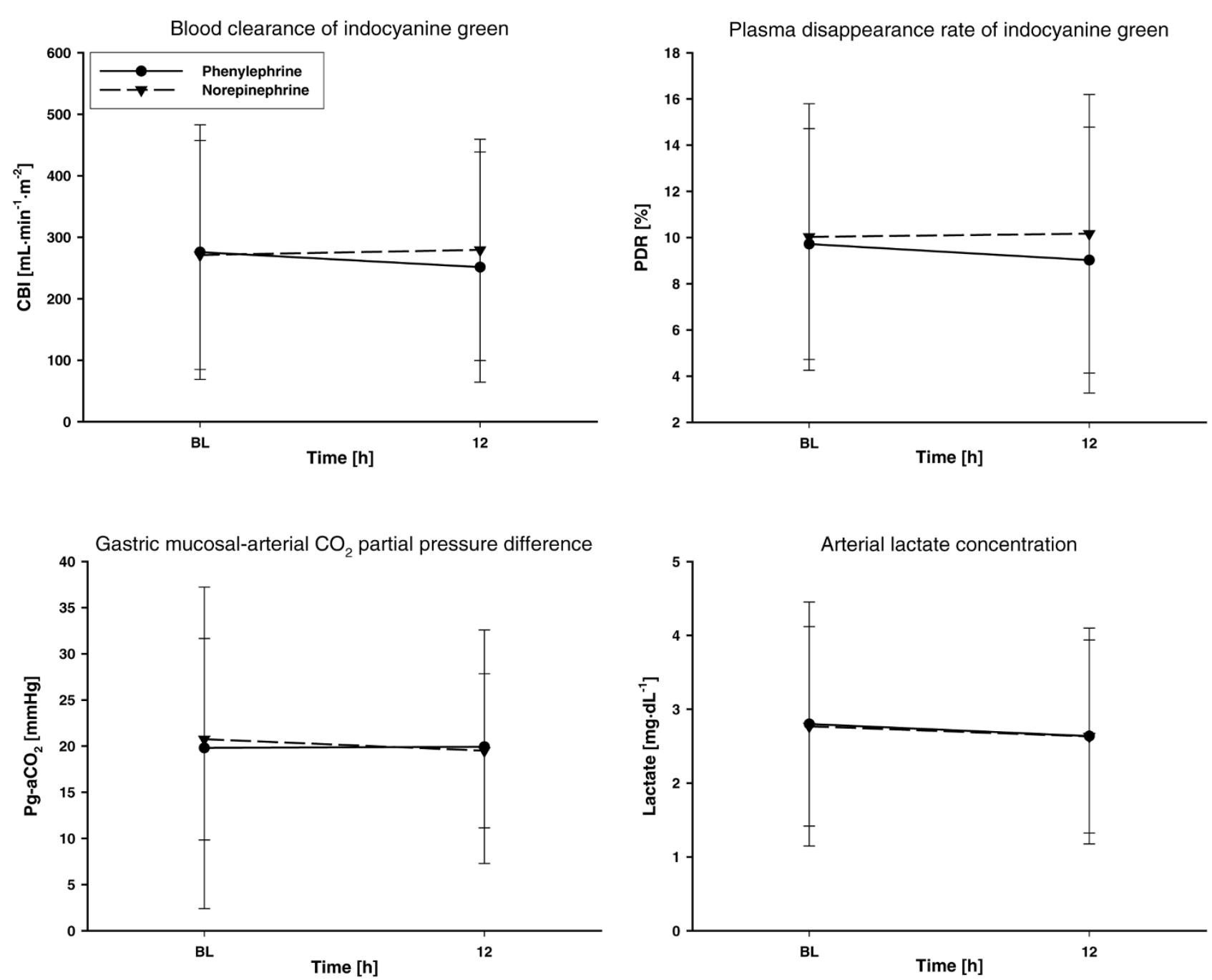

Regional hemodynamics of study patients. Patients' blood clearance of indocyanine green related to body surface area (CBI), plasma disappearance rate of indocyanine green (PDR), gradient between gastric mucosal and arterial $\mathrm{pCO}_{2}\left(\mathrm{p}_{\mathrm{g}-\mathrm{a}} \mathrm{CO}_{2}\right)$, and arterial lactate concentration throughout the study. BL, baseline.

istration of phenylephrine at the time of shock onset could have played a pivotal role in this regard $[12,27]$.

The effects of phenylephrine on renal function have not yet been fully elucidated. We recently reported that delayed administration of phenylephrine replacing norepinephrine in a series of septic shock patients negatively affected renal function, as indicated by a decrease in creatinine clearance compared with norepinephrine administration [8]. In the present study, we noticed no differences between the two study drugs in terms of urine output or creatinine clearance. The number of patients who required renal replacement therapy at the end of the 12-hour study period, however, although not statistically significant, tended to be higher in the phenylephrine group (7 patients versus 2 patients, $P=0.133$ ). Although speculative, this finding supports the notion that mixed $\alpha$-adrenergic and $\beta$ adrenergic agents when given to increase or maintain the MAP may better preserve renal blood flow as compared with sole $\alpha$ agonists [28-31]. Nevertheless, the implication of this finding for the course of the disease remains uncertain and should be clarified in future studies.

The present study has some limitations that we would like to acknowledge. First, direct measurements of regional and local splanchnic blood flow in septic shock patients are invasive and require special skills and instruments that are not readily available at the bedside. In the present study, therefore, hepatosplanchnic perfusion was assessed using the PDR, CBI, and 
Table 3

Global oxygen transport variables and acid-base balance of study patients

\begin{tabular}{|c|c|c|c|}
\hline & Baseline & 12 hours & $P$ value \\
\hline Oxygen delivery index $\left(\mathrm{ml} / \mathrm{min} / \mathrm{m}^{2}\right)$ & & & 0.951 \\
\hline Phenylephrine & $500 \pm 205$ & $498 \pm 177$ & \\
\hline Norepinephrine & $499 \pm 139$ & $506 \pm 140$ & \\
\hline Oxygen consumption index $\left(\mathrm{ml} / \mathrm{min} / \mathrm{m}^{2}\right)$ & & & 0.568 \\
\hline Phenylephrine & $164 \pm 48$ & $150 \pm 41$ & \\
\hline Norepinephrine & $173 \pm 53$ & $161 \pm 58$ & \\
\hline Oxygen extraction ratio (\%) & & & 0.816 \\
\hline Phenylephrine & $34 \pm 9$ & $32 \pm 8$ & \\
\hline Norepinephrine & $36 \pm 11$ & $32 \pm 10^{*}$ & \\
\hline Hemoglobin (g/dl) & & & 0.699 \\
\hline Phenylephrine & $8.4 \pm 0.9$ & $8.4 \pm 1.1$ & \\
\hline Norepinephrine & $8.3 \pm 0.7$ & $8.4 \pm 0.6$ & \\
\hline $\mathrm{pHa}\left(-\log _{10} \mathrm{c}\left(\mathrm{H}^{+}\right)\right)$ & & & 0.435 \\
\hline Phenylephrine & $7.37 \pm 0.07$ & $7.37 \pm 0.08$ & \\
\hline Norepinephrine & $7.35 \pm 0.09$ & $7.34 \pm 0.08$ & \\
\hline Arterial base excess (mmol/l) & & & 0.228 \\
\hline Phenylephrine & $-0.2 \pm 5.8$ & $0.2 \pm 6.3$ & \\
\hline Norepinephrine & $-2.4 \pm 6.6$ & $-3.0 \pm 6.4$ & \\
\hline Arterial carbon dioxide partial pressure $(\mathrm{mmHg})$ & & & 0.346 \\
\hline Phenylephrine & $44 \pm 10$ & $44 \pm 10$ & \\
\hline Norepinephrine & $41 \pm 6$ & $41 \pm 6$ & \\
\hline Arterial oxygen partial pressure $(\mathrm{mmHg})$ & & & 0.963 \\
\hline Phenylephrine & $128 \pm 36$ & $119 \pm 31$ & \\
\hline Norepinephrine & $121 \pm 24$ & $120 \pm 26$ & \\
\hline Arterial oxygen saturation (\%) & & & 0.912 \\
\hline Phenylephrine & $98 \pm 2$ & $98 \pm 2$ & \\
\hline Norepinephrine & $98 \pm 1$ & $98 \pm 2$ & \\
\hline Mixed venous oxygen saturation (\%) & & & 0.431 \\
\hline Phenylephrine & $66 \pm 9$ & $67 \pm 9$ & \\
\hline Norepinephrine & $64 \pm 11$ & $67 \pm 10$ & \\
\hline $\mathrm{P}_{\mathrm{a}} \mathrm{O}_{2} / \mathrm{FiO}_{2}$ & & & 0.971 \\
\hline Phenylephrine & $229 \pm 103$ & $208 \pm 89$ & \\
\hline Norepinephrine & $222 \pm 75$ & $218 \pm 71$ & \\
\hline
\end{tabular}
$\mathrm{P}_{\mathrm{a}} \mathrm{O}_{2} / \mathrm{FiO}_{2}$, ratio of arterial oxygen partial pressure and inspiratory oxygen fraction (Horovitz index). ${ }^{\star} P<0.05$ versus baseline (significant time
effect). 
Figure 5
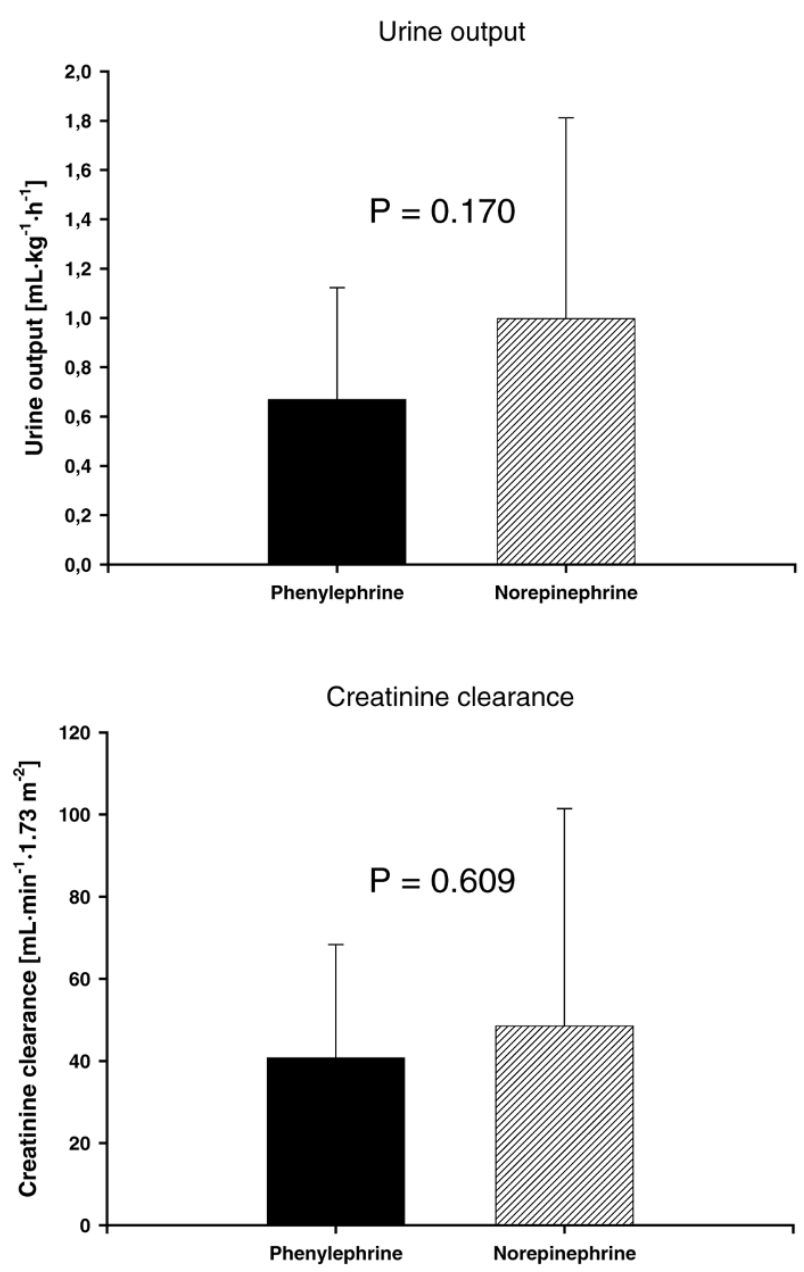

Variables of renal function. Urine output and creatinine clearance in the two treated patient groups.

gastric tonometry as surrogates of hepatosplanchnic perfusion and function. Second, as phenylephrine was administered as a first-line vasopressor agent in the present study, for safety reasons we investigated only a small number of septic shock patients to evaluate the effects on cardiopulmonary and regional hemodynamics over a relative brief period (that is, 12hour intervention period). We therefore cannot rule out the possibility of adverse metabolic alterations or worsening of hepatosplanchnic perfusion in response to administration of phenylephrine for a prolonged period. Third, even though it was possible to define the exact time when the enrolled patients required vasopressor support during the ICU stay, we cannot exclude differences in the time of onset of sepsis before ICU admission. Finally, since the present study was powered to demonstrate a $30 \%$ difference in the PDR and $\mathrm{CBI}$, smaller differences, even though of scarce clinical implications, cannot be excluded by the present data. This question can only be answered by studies investigating a larger sample size.

\section{Conclusion}

This is the first prospective, randomized, controlled study comparing systemic and regional hemodynamic effects of phenylephrine and norepinephrine infusion in the early phase of septic shock. Our results suggest that phenylephrine - when administered as a first-line vasopressor agent in septic shock - is effective in increasing the MAP without compromising gastrointestinal and hepatosplanchnic perfusion as compared with norepinephrine.

\section{Key messages}

- There are no differences between norepinephrine and phenylephrine in terms of systemic hemodynamics when they are administered as a first-line vasopressor agent in septic shock.

- Phenylephrine is less effective than norepinephrine to counteract sepsis-related arterial hypotension.

- Phenylephrine does not impair gastrointestinal mucosal perfusion.

- Delayed administration of phenylephrine in septic shock patients causes a more pronounced hepatosplanchnic vasoconstriction as compared with norepinephrine.

- Phenylephrine - when administered as a first-line vasopressor agent in septic shock - is effective for increasing the MAP without compromising gastrointestinal and hepatosplanchnic perfusion, as compared with norepinephrine administration.

\section{Competing interests}

The authors declare that they have no competing interests.

\section{Authors' contributions}

$\mathrm{AM}$ and $\mathrm{MW}$ conceived of the study, were responsible for its design and coordination, and helped to draft the manuscript. $\mathrm{CE}, \mathrm{ML}, \mathrm{SR}$, and HVA participated in the design of the study, performed the statistical analysis, and helped to draft the manuscript. $A O$ and $A L$ participated in the study design and helped to draft the manuscript. $A B$ and MD participated in the study design, performed laboratory measurements, and helped to draft the manuscript. PP participated in the study design and coordination, helped to draft the manuscript, and obtained funding. All authors read and approved the final manuscript.

\section{Acknowledgements}

The present study was funded by an independent research grant from the Department of Anesthesiology and Intensive Care of the University of Rome 'La Sapienza'. 


\section{References}

1. Dellinger RP, Levy MM, Carlet JM, Bion J, Parker MM, Jaeschke R, Reinhart K, Angus DC, Brun-Buisson C, Beale R, Calandra T, Dhainaut JF, Gerlach H, Harvey M, Marini JJ, Marshall J, Ranieri M, Ramsay G, Sevransky J, Taylor Thompson B, Townsend S, Vender JS, Zimmerman JL, Vincent JL: Surviving Sepsis Campaign: international guidelines for management of severe sepsis and septic shock: 2008. Crit Care Med 2008, 36:296-327.

2. Reinelt H, Radermacher P, Kiefer P, Fischer G, Wachter U, Vogt J, Georgieff M: Impact of exogenous beta-adrenergic receptor stimulation on hepatosplanchnic oxygen kinetics and metabolic activity in septic shock. Crit Care Med 1999, 27:325-331.

3. Beale RJ, Hollenberg SM, Vincent JL, Parrillo JE: Vasopressor and inotropic support in septic shock: an evidence-based review. Crit Care Med 2004, 32(11 Suppl):S455-S465.

4. Gregory JS, Bonfiglio MF, Dasta JF, Reilley TE, Townsend MC, Flancbaum L: Experience with phenylephrine as a component of the pharmacologic support of septic shock. Crit Care Med 1991, 19:1395-1400.

5. Flancbaum L, Dick M, Dasta J, Sinha R, Choban P: A doseresponse study of phenylephrine in critically ill, septic surgical patients. Eur J Clin Pharmacol 1997, 51:461-465.

6. Hofmann BB, Lefkowitz RJ: Catecholamines and sympathomimetic drugs. In Goodman and Gilman's the pharmacological basis of therapeutics Edited by: Alfred Gilman, Louis S Goodman, Brian B Hoffman, Robert J Lefkowitz. New York: Pergamon; 1991:187-220.

7. Krejci V, Hiltebrand LB, Sigurdsson GH MD: Effects of epinephrine, norepinephrine, and phenylephrine on microcirculatory blood flow in the gastrointestinal tract in sepsis. Crit Care Med 2006, 34:1456-1463.

8. Morelli A, Lange M, Ertmer C, Dünser M, Rehberg S, Bachetoni A, D'Alessandro M, Van Aken H, Guarracino F, Pietropaoli P, Traber DL, Westphal M: Short-term effects of phenylephrine on systemic and regional hemodynamics in patients with septic shock: a crossover pilot study. Shock 2008, 29:446-451.

9. Rivers E, Nguyen B, Havstad S, Ressler J, Muzzin A, Knoblich B, Peterson E, Tomlanovich M, Early Goal-directed Therapy Collaborative Group: Early goal-directed therapy in the treatment of severe sepsis and septic shock. N Engl J Med 2001, 345:1368-1377.

10. Rivers EP, Kruse JA, Jacobsen G, Shah K, Loomba M, Otero R, Child EW: The influence of early hemodynamic optimization on biomarker patterns of severe sepsis and septic shock. Crit Care Med 2007, 35:2016-2024.

11. Parrillo JE: Septic shock - vasopressin, norepinephrine, and urgency. N Engl J Med 2008, 358:954-956.

12. Sakka SG, Reinhart K, Meier-Hellmann A: Prognostic value of the indocyanine green plasma disappearance rate in critically ill patients. Chest 2002, 122:1715-1720.

13. Sakka SG, van Hout N: Relation between indocyanine green (ICG) plasma disappearance rate and ICG blood clearance in critically ill patients. Intensive Care Med 2006, 32:766-769.

14. Creteur J, De Backer D, Vincent JL: Monitoring gastric mucosal carbon dioxide pressure using gas tonometry: in vitro and in vivo validation studies. Anesthesiology 1997, 87:504-510.

15. Groeneveld AB, Kolkman JJ: Splanchnic tonometry: a review of physiology, methodology, and clinical applications. J Crit Care 1994, 9:198-210.

16. Winer BJ, Brown DR, Michels KM: Statistical principles in experimental design. 3rd edition. New York: McGraw-Hill; 1991.

17. Sander O, Welters ID, Foex P, Sear JW: Impact of prolonged elevated heart rate on incidence of major cardiac events in critically ill patients with a high risk of cardiac complications. Crit Care Med 2005, 33:81-88.

18. Schwarz B, Hofstötter $H$, Salak N, Pajk N, Knotzer $H$, Mayr A, Labek B, Kafka R, Ulmer H, Hasibeder W: Effects of norepinephrine and phenylephrine on intestinal oxygen supply and mucosal tissue oxygen tension. Intensive Care Med 2001, 27:593-601.

19. Zhang H, Smail N, Cabral A, Rogiers P, Vincent JL: Effects of norepinephrine on regional blood flow and oxygen extraction capabilities during endotoxin shock. Am J Respir Crit Care Med 1997, 155:1965-1971.

20. Alia I, Esteban A, Gordo F, Lorente JA, Diaz C, Rodriguez JA, Frutos $F$ : A randomized and controlled trial of the effect of treat- ment aimed at maximizing oxygen delivery in patients with severe sepsis or septic shock. Chest 1999, 115:453-461.

21. Meier-Hellmann A, Specht M, Hannemann L, Hassel H, Bredle DL, Reinhart K: Splanchnic blood flow is greater in septic shock treated with norepinephrine than in severe sepsis. Intensive Care Med 1996, 22:1354-1359.

22. Duranteau J, Sitbon P, Teboul JL, Vicaut E, Anguel N, Richard C, Samii K: Effects of epinephrine, norepinephrine, or the combination of norepinephrine and dobutamine on gastric mucosa in septic shock. Crit Care Med 1999, 27:893-900.

23. Marik PE, Mohedin M: The contrasting effects of dopamine and norepinephrine on systemic and splanchnic oxygen utilization in hyperdynamic sepsis. JAMA 1994, 272:1354-1357.

24. Levy B, Bollaert PE, Charpentier C, Nace L, Audibert G, Bauer PH Nabet $P$, Larcan A: Comparison of norepinephrine and dobutamine to epinephrine for hemodynamics, lactate metabolism, and gastric tonometric variables in septic shock: a prospective, randomized study. Intensive Care Med 1997, 23:282-287.

25. Breslow MJ, Miller CF, Parker SD, Walman AT, Traystman RJ: Effect of vasopressors on organ blood flow during endotoxin shock in pigs. Am J Physiol 1987, 252: $\mathrm{H} 291-\mathrm{H} 300$.

26. Zhang $H$, De Jongh $R$, De Backer D, Cherkaoui $S$, Vray B, Vincent $\mathrm{JL}$ : Effects of $\alpha$ - and $\beta$-adrenergic stimulation on hepatosplanchnic perfusion and oxygen extraction in endotoxic shock. Crit Care Med 2001, 29:581-588.

27. Levy MM, Macias WL, Vincent JL, Russell JA, Silva E, Trzaskoma $B$, Williams MD: Early changes in organ function predict eventual survival in severe sepsis. Crit Care Med 2005, 33:2194-2201.

28. Bersten AD, Rutten AJ: Renovascular interaction of epinephrine, dopamine and intraperitoneal sepsis. Crit Care Med 1995, 23:537-544

29. Bersten $A D$, Rutten $A J$, Summersides $G$, Ilsley $A H$ : Epinephrine infusion in sheep: systemic and renal hemodynamic effects. Crit Care Med 1994, 22:994-1001.

30. Bellomo R, Kellum JA, Wisiniewsky SR, Pinsky MR: Effects of norepinephrine on the renal vasculature in normal and endotoxemic dogs. Am J Respir Crit Care Med 1999, 159:1186-1192.

31. Bellomo R: Noradrenaline: friend or foe? Heart Lung Circ 2003, 12:S42-S48. 